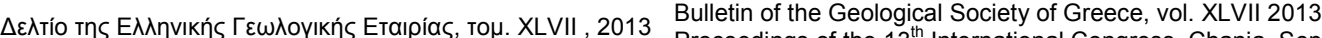
$\triangle 1$ Proceedings of the $13^{\text {th }}$ International Congress, Chania, Sept.

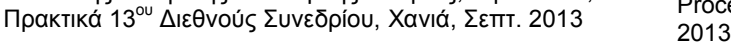

\title{
OBTAINING INFORMATION ON THE Q-STRUCTURE OF THE SOUTHERN AEGEAN SUBDUCTION AREA BY SPECTRAL SLOPES FROM TEMPORARY AND PERMANENT NETWORKS
}

\author{
Ventouzi Ch. ${ }^{1}$, Papazachos $C .{ }^{1}$, Papaioannou $C h .{ }^{2}$, Hatzidimitriou $P^{1}$. and the \\ EGELADOS working group

\footnotetext{
${ }^{I}$ Aristotle University of Thessaloniki, Faculty of Science, Department of Geology, Geophysical Laboratory,xrusven@geo.auth.gr,kpapaza@geo.auth.gr,chdimitr@geo.auth.gr
} \\ ${ }^{2}$ Institute of Engineering Seismology \& Earthquake Engineering, Thessaloniki, chpapai@itsak.gr
}

\begin{abstract}
Anelastic attenuation studies have been considered one of the main controlling factors affecting seismic wave propagation, providing important information on the earth's structure. In order to investigate the attenuation structure of the southern Aegean subduction area, we employed $\sim 400$ intermediate depth earthquakes recorded by temporary and permanent networks. Using the recorded waveforms we have calculated a frequency-independent path attenuation operator $t^{*}$ for both $P$ and $S$ waves. Initially an automated method was employed, where $t^{*}$ was automatically calculated by the slope of the acceleration spectrum produced above the corner frequency, $f_{c}$. Computations were performed in the $0.2-25 \mathrm{~Hz}$ frequency band, using only spectra with a signal to noise ratio greater than 3 , and above the noise level for at least the range $1-4 \mathrm{~Hz}$ (for $S$ and $P$ waves, respectively). In the second approach, the selection of the segment of the spectrum was carried out manually for optimum fitting. No considerable linear trend revealing dependence of $t^{*}$ with distance could be observed on the original data, whereas strong clustering for different focal depth ranges was observed. The spatial variation of the obtained $t^{*}$ values shows that, in general, along-arc stations present low values of $t^{*}$, while back-arc stations show much larger values. The observed $t^{*}$ difference becomes more pronounced as the depth of the earthquakes increases, suggesting a significant localized effect of the high-attenuation (low- $Q$ ) mantle wedge, in agreement with independent observations.
\end{abstract}

Key words: Anelastic attenuation, Quality factor, EGELADOS experiment.

\section{Пврі́ $\eta \psi \eta$}

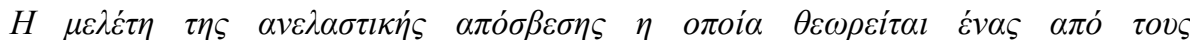

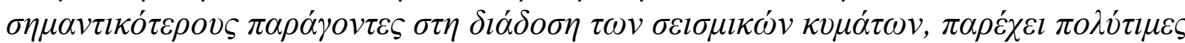

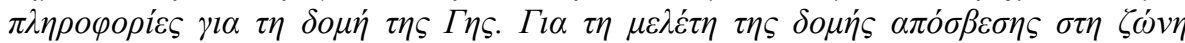

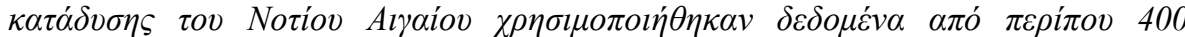

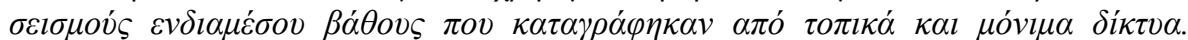

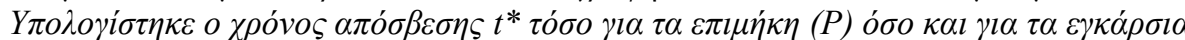

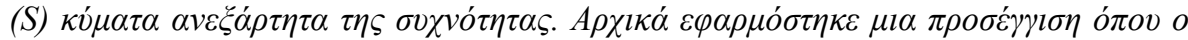

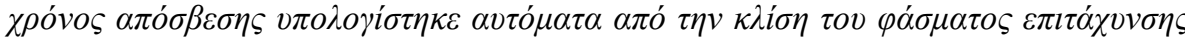

XLVII, No 3 - 1366 


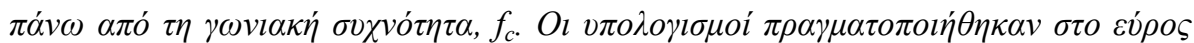

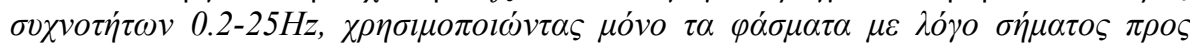

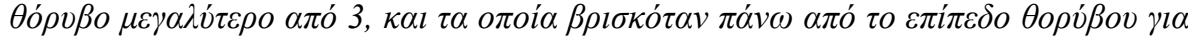

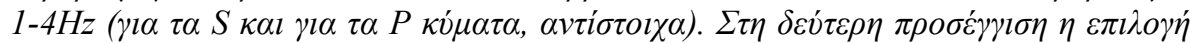

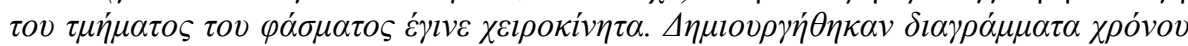

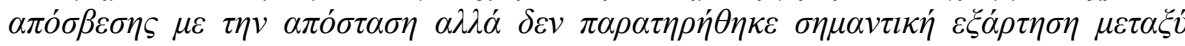

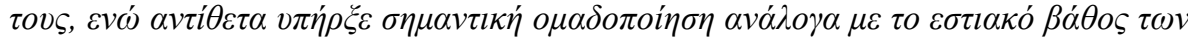

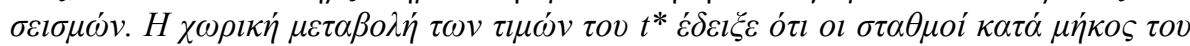

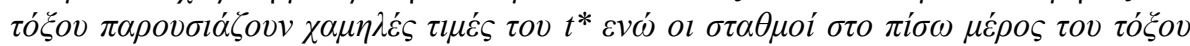

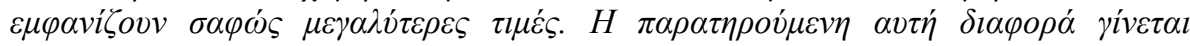

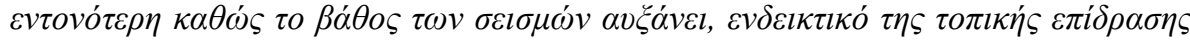

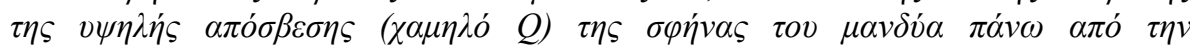
$\kappa \alpha \tau \alpha \delta v o ́ \mu \varepsilon v \eta \lambda \imath \theta o ́ \sigma \varphi \alpha \imath \rho \alpha, \sigma \varepsilon \sigma v \mu \varphi \omega v i ́ \alpha \mu \varepsilon \alpha v \varepsilon \xi \dot{\alpha} \rho \tau \eta \tau \varepsilon \varsigma \pi \alpha \rho \alpha \tau \eta \rho \dot{\sigma} \sigma \varepsilon l \varsigma$.

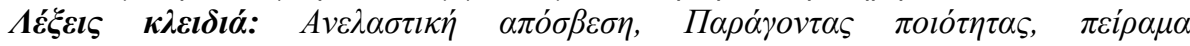
EГKE $\Lambda A \triangle O \Sigma$.

\section{Introduction}

The under study area of the Southern Aegean is located where the eastern Mediterranean lithosphere subducts under the Aegean and the Aegean micropale overrides the Eastern Mediterranean along an active plate boundary forming the Hellenic Arc (Papazachos and Delibasis, 1969; Papazachos and Comninakis, 1971; McKenzie, 1972). Intermediate depth earthquakes occur at depths ranging between 60 to 180km (Papazachos et al., 2000) along a welldefined Wadati-Benioff Zone (Figure 1). Several studies on active tectonics of the area have been already done using seismological and geodetic data (Papazachos and Comninakis, 1971; Oral et al., 1995; Reilinger et al., 1997; Papazachos et al, 1999; McClusky et al., 2000) revealing that the subduction of the African plate beneath Crete which occurs at a rate of $35 \mathrm{~mm} / \mathrm{yr}$, exceeds the convergence between Africa and Eurasia $(5-10 \mathrm{~mm} / \mathrm{yr})$, due to the fact that Southern Aegean moves more rapidly to the SW direction.

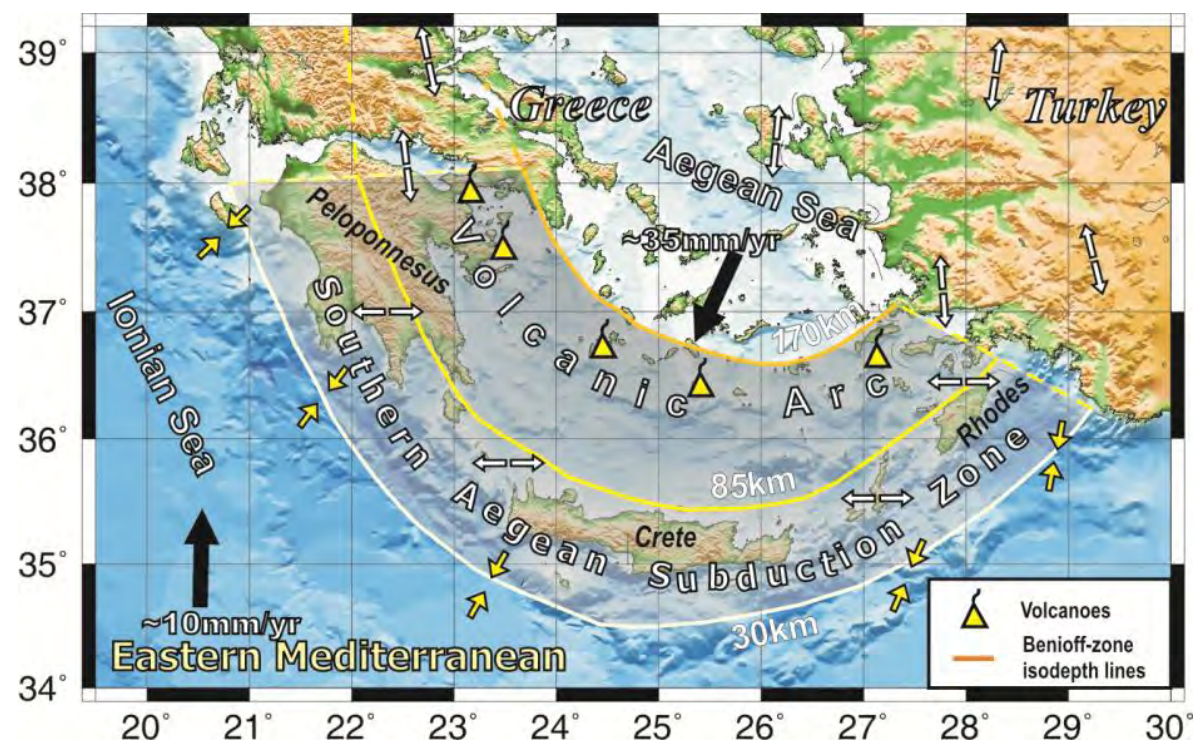

Figure 1 - Geotectonic setting of the broader Southern Aegean subduction area. Isodepths of the Benioff-zone, as well as the volcanic arc are shown. Single solid and double open vectors depict the plate motions and local stress field in the area, respectively (modified from Papazachos et al. 1998, Karagianni et al., 2005).

$\underline{\text { XLVII, No } 3 \text { - } 1367}$ 
Anelastic attenuation studies are an important tool in complicated tectonic environments such as subduction zones, as they provide valuable information on subduction dynamics including slab dehydration and melt transport (Schurr et al., 2003; Pozgay et al., 2009), on the earth's interior including mantle wedge temperature (Stachnik et al., 2004; Pozgay et al., 2009) and the degree of partial melting. Seismic wave propagation is mainly controlled by attenuation which plays a significant role in strong ground motion predictions. It is therefore of high importance to understand the attenuation structure in the Hellenic subduction system. In the present study highquality seismic data of intermediate-depth events from the large-scale local network of EGELADOS project are used in order to investigate the anelastic attenuation (Q) structure of the southern Aegean subduction system.

\section{Data Used}

The EGELADOS seismic monitoring project was a large-scale temporary amphibian broadband seismological network, consisted of 65 land stations and 24 ocean-bottom (OBS) recorders installed in the southern Aegean area. It operated from October 2005 until April 2007 by a large working group including the Aristotle University of Thessaloniki, the National Observatory of Athens, Technical University of Chania, Istanbul Technical University, University of Hamburg and GeoForschungszentrum Potsdam. Data from another local network were also taken into account for the research of the attenuation structure. CYCNET (Bohnhoff et al., 2004) was a digital broad-band/short period 22-station temporary seismic network installed in the central Hellenic Arc, in the Cyclades island group, which was in operation from September 2002 until September 2005. Finally recordings from the permanent networks of National Observatory of Athens and GEOFON were also included. The station distribution of all the above mentioned networks is shown in Figure 2. Red squares represent stations from EGELEDOS network; blue triangles show broadband stations from CYCNET network while inverted blue triangles display short-period sensors. Stations from the permanent seismological networks (NOA and GEOFON) appear with yellow stars and purple diamonds respectively. Finally the Ocean Bottom (OBS) instruments are denoted with green circles.

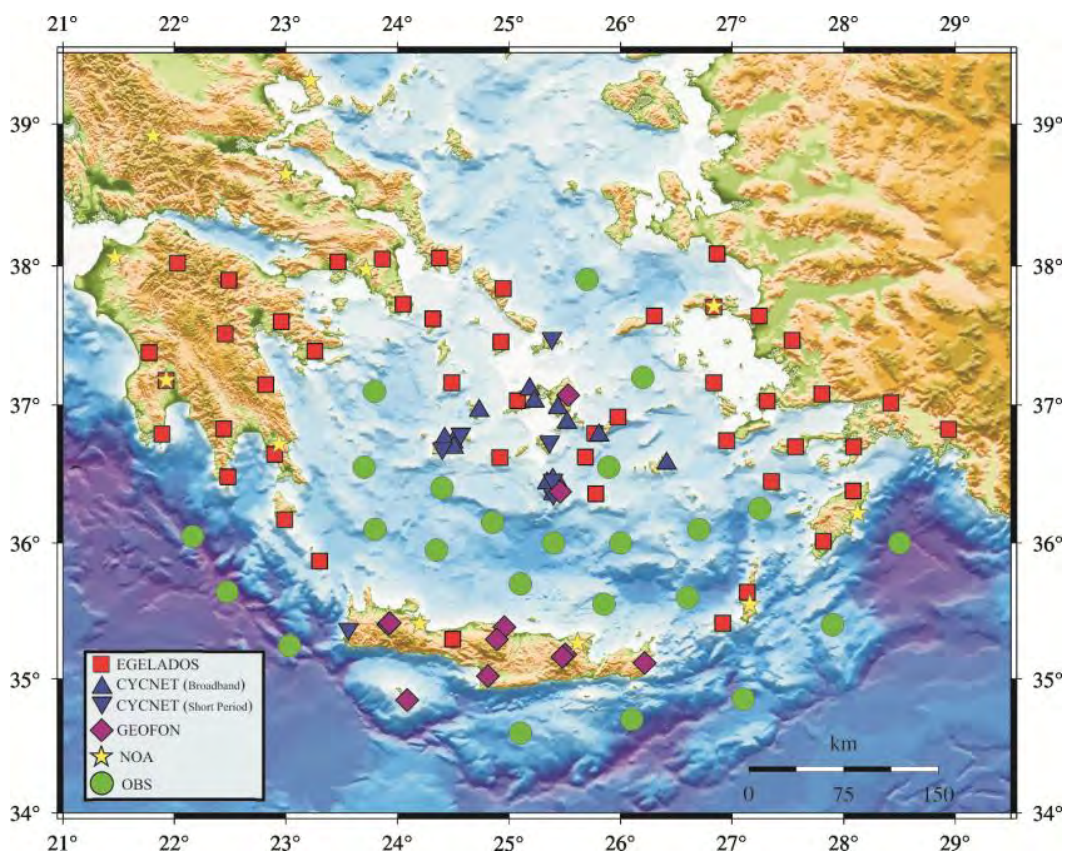

Figure 2 - Station distribution of all networks (temporary and permanent) used in the present study.

$\underline{\text { XLVII, No } 3-1368}$ 
Data from these two experiments, together with the recordings of the permanent networks provided a large data set of high quality for studying the attenuation structure of the Hellenic Subduction Zone. About 400 intermediate-depth local events recorded by the on-land stations were finally adopted for the present study from the whole data set from both temporary and permanent networks. The epicentral, as well as the depth distribution, of the earthquakes studied is displayed in Figure 3.

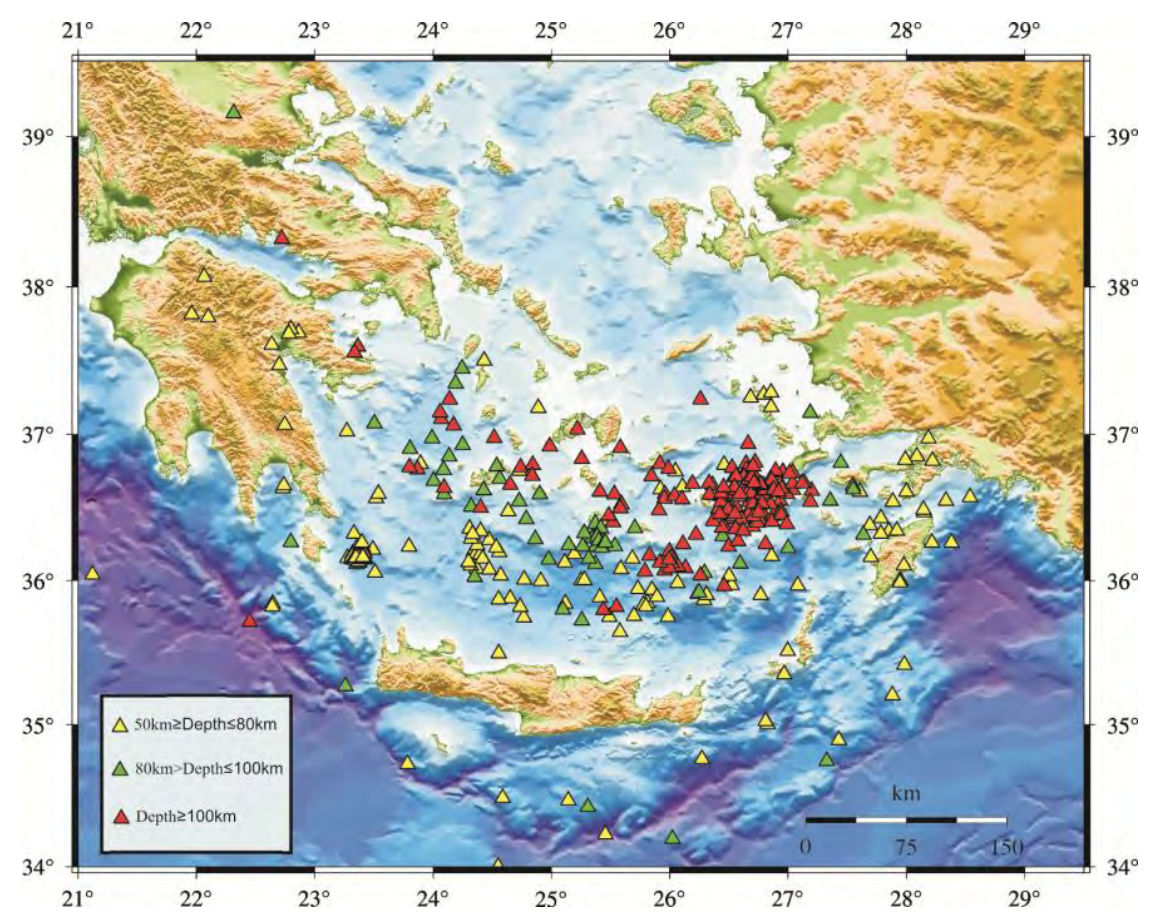

Figure 3 - Epicentral and depth distribution of all intermediate depth earthquakes employed for the Southern Aegean attenuation structure.

\section{Estimating Attenuation Operator}

Inelastic attenuation, i.e. the deviation of the behaviour of the Earth from a perfect elastic body, provides interesting information about the Earth's structure and in conjunction with geometrical spreading is a key factor in seismic wave propagation. Intrinsic attenuation is commonly described by the quality factor (Q-factor) which is the loss of elastic energy of a seismic wave while it propagates through an inelastic medium and can be defined as:

Equation 1 - Quality factor

(1) $Q=-\frac{2 \pi E}{\Delta E}$

where $\mathrm{E}$ is the energy of the seismic wave and $\Delta \mathrm{E}$ is the amount of energy lost over a period or a wavelength. Due to this energy loss the amplitudes of seismic waves are reduced while they travel through Earth proportional to the quality factor. Therefore, the amplitude A of a wave at a distance $r$ is given by Equation 2 .

Equation 2 - Amplitude of a seismic wave at a distance $r$

(2) $A=\frac{A_{0}}{r} \exp \left(-\frac{\pi f}{Q V} r\right)$ 
In order to determine the quality factor we need to calculate the whole path attenuation operator $t^{*}$ for propagating seismic waves from the source to the recording station, which is given by (Equation 3).

\section{Equation 3 - Whole path attenuation operator}

(3) $t^{*}=\int_{p a t h} \frac{d y}{Q V} \quad($ Kanamori, 1967)

The whole path attenuation operator $\mathrm{t}^{*}$ can be estimated from the slope of the amplitude spectrum above corner frequency $f_{c}$, by applying Fourier transformation (Cormier, 1982) according to (Equa tion 4).

\section{Equation 4 - Fourier transformation spectrum}

(4) $A(r, f)=A_{0} \exp \left(-\pi f t^{*}\right)$ where

$$
A_{0}=(2 \pi f)^{2} S(f) G(r, f)
$$

In equation (4) $G(r, f)$ is the geometrical spreading factor and $S(f)$ is the displacement source spectrum which assuming a Brune type source (Brune, 1970), is proportional to the corner frequency $f_{c}$. If we consider that the quality factor $Q$ remains constant throughout the whole raypath, then equation 3 becomes:

\section{Equation 5 - Whole path attenuation operator}

(5) $t^{*}=\frac{t}{Q}$

Replacing the above relation in equation 4 we get (equation 6):

\section{Equation 6 - Spectral slope estimation}

(6) $\ln [A(f)]=\ln A_{0}-\pi f t / Q$

which is a linear equation with slope $\pi t / Q$. By finding the slope of this linear equation we can practically compute the mean quality factor, $Q$, along the raypath since the $(2 \pi f)^{2} S(f)$ factor remains constant at frequencies above the $f_{c}$ in acceleration spectrum and the geometrical spreading factor, $G(r, f)$, is considered to be depended only by distance.

In order to determine attenuation operator we need to know the arrival times of $\mathrm{P}$ and $\mathrm{S}$ waves respectively. Unfortunately, this information was not available for all recordings. For this reason we generated estimated arrival times as a function of epicentral distance, for different groups of focal depths, calculated from data provided by the CYCNET experiment. Figure 4 demonstrates the estimated arrival times as a function of epicentral distance for different groups of focal depth, and for both $\mathrm{P}$ and $\mathrm{S}$ waves.

Initially all available arrival times (original and estimated) were imported in the velocity waveforms for all three components and then differentiated to yield to the corresponding acceleration waveforms. We then obtained the amplitude spectra of $5 \%$ tapered $\mathrm{P}$ and $\mathrm{S}$ acceleration waveforms by applying the fast Fourier transform. The amplitude spectra were calculated for a $5 \mathrm{sec}$ time window after the $\mathrm{P}$ and $\mathrm{S}$ arrival times. Noise spectrum was also calculated $5 \mathrm{sec}$ before $\mathrm{P}$ and $5 \mathrm{sec}$ before $\mathrm{S}$ arrival in order to estimate the signal-to-noise ratio and apply a quality control procedure. In order to obtain precise estimates of $t^{*}$, we applied certain selection criteria. Therefore, we considered waveforms only if the amplitude of the acceleration spectrum was at least 3 times larger than the spectrum of the background noise for both $\mathrm{P}$ and $\mathrm{S}$ waves. In addition, only data with a frequency bandwidth greater than $4 \mathrm{~Hz}$ for $\mathrm{P}$ waves and greater than $1 \mathrm{~Hz}$ for $\mathrm{S}$ waves were processed. The lower limit of the frequency band that was considered for all calculations was $0.2 \mathrm{~Hz}$ and the corresponding upper limit was set to $25 \mathrm{~Hz}$ to reduce the effect of high-frequency noise. 

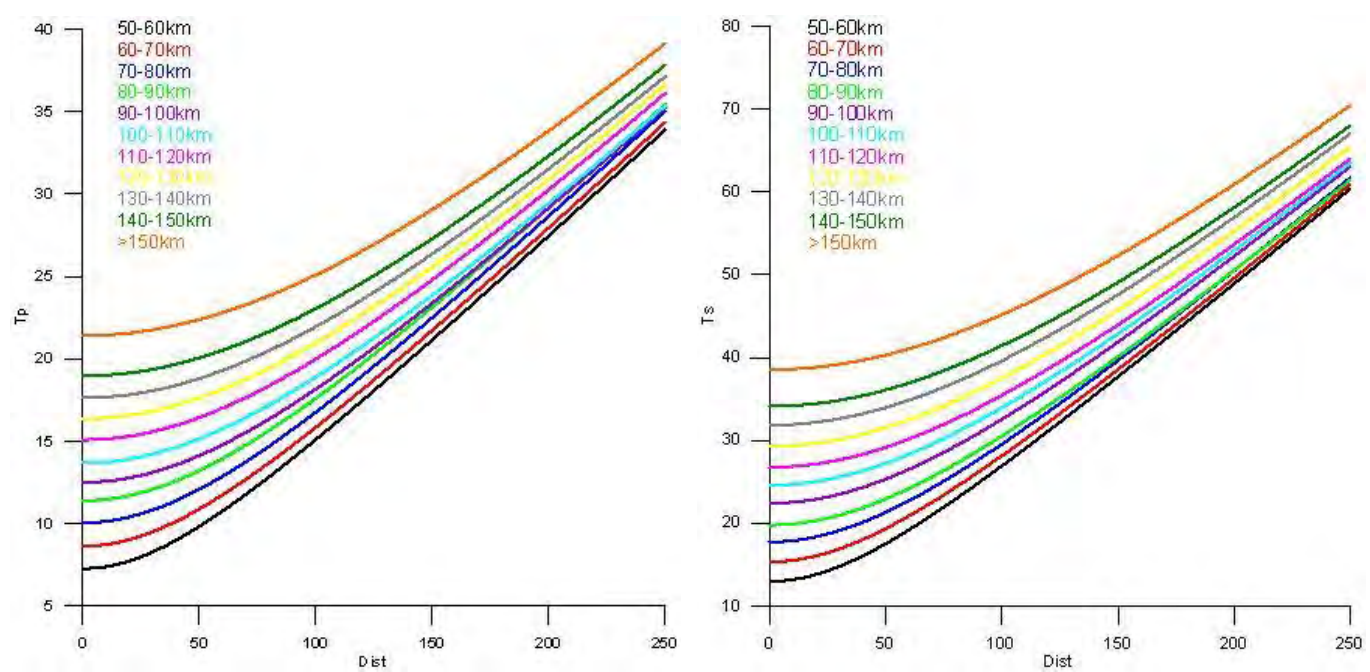

Figure 4 - Estimated arrival times of $P$ (left) and $S$ (right) waves in relation to epicentral distance for different focal depths.

To determine $t^{*}$, we have adopted two independent approaches. Initially an automated method was used, where $t^{*}$ was automatically calculated by the slope of the acceleration spectrum produced above the corner frequency, $f_{c}$. In the second approach, the selection of the segment of the spectrum for the $t^{*}$ estimation was carried out manually, by interactively picking each spectral

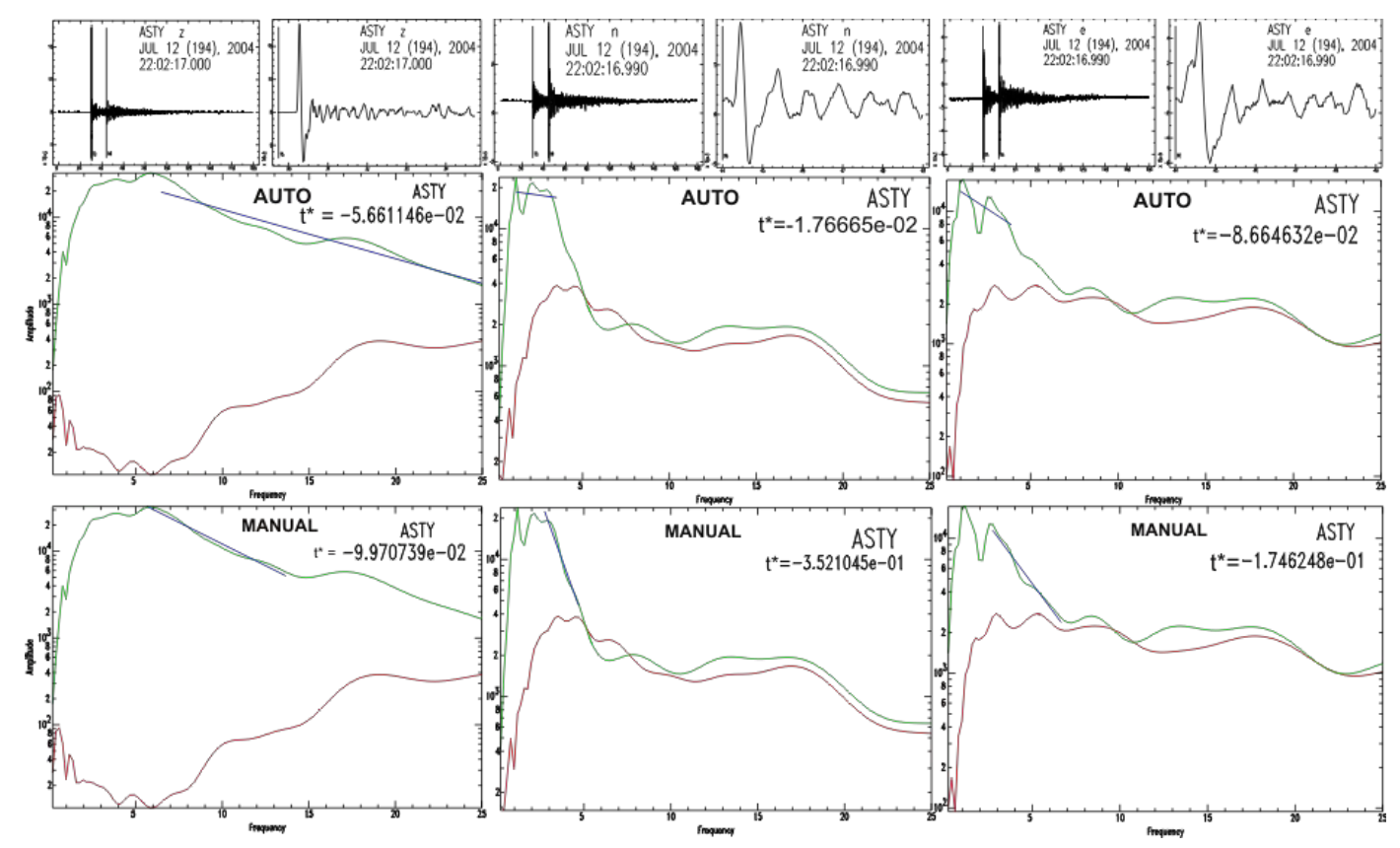

Figure 5 - Example of $P$ and $S$ velocity waveforms from one intermediate depth earthquake recorded by three-component station ASTY (CYC-NET network) as well as the best-fit linear slopes calculated both manually and automatic. The top frame shows the velocity waveform and the 5 sec signal starting from the origin time. The middle frame shows the observed noise spectrum (red), the observed signal spectrum (green) and the best fitting line (blue) using the automatic approach, while bottom frame using the manual one. The calculated $t$ * values are also listed.

XLVII, No 3 - 1371 


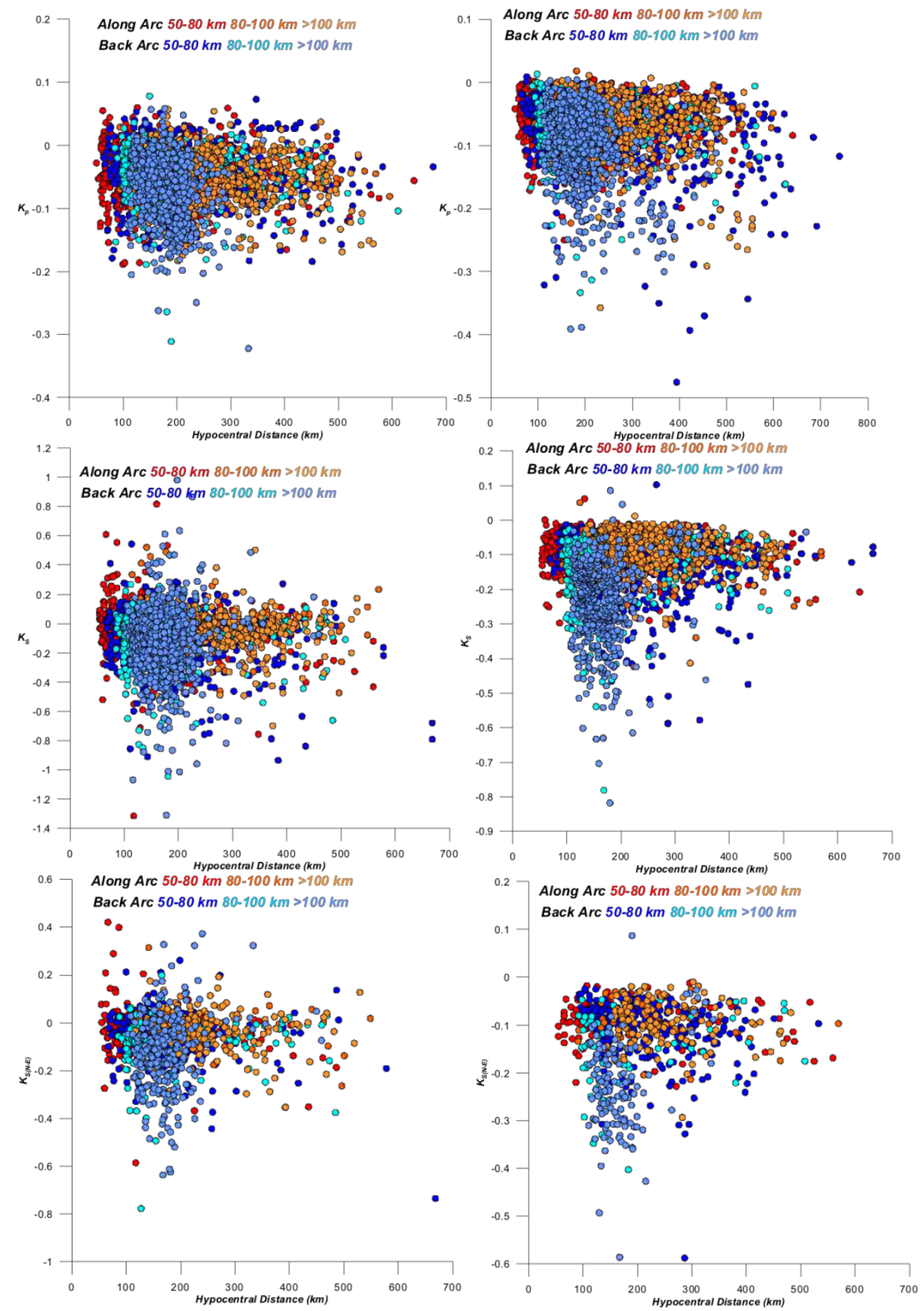

Figure 6 - Plots of $t^{*}$ versus hypocentral distance for $P$ and $S$ waves for all stations and for all intermediate depth events recorded and calculated with both approaches. On the left, the results from the automated method are presented, while on the right the results from the manual approach are shown. Top frame shows slope fits from P-waves, middle frame from $S$ waves and bottom frame average $S$-wave slopes from both horizontal coordinates, when both where available. Back-arc stations have larger slope values revealing high attenuation in the area, similarly to deeper events $(\mathrm{h}>100 \mathrm{~km})$, which show the most pronounced attenuation effects. 
frequency band over which to calculate $t^{*}$, ensuring at the same time that the frequencies are within the limits previously defined, and that the signal-to-noise ratio was above the desired level for optimum fitting. An example of velocity waveforms from one station with Z, N-S and E-W components with the appropriate fitting to the acceleration spectra produced, using both methods, is shown in Figure 5.

In order to examine the variation of $t^{*}$ with distance, plots of the estimated $t^{*}$ versus the hypocentral distance constructed using all the available data for both $\mathrm{P}$ and $\mathrm{S}$ waves. Moreover, following Skarlatoudis et al. (2013), data were sorted into three different depth categories (50 $\leq$ depth $\leq 80 \mathrm{~km}, 80 \leq$ depth $\leq 100 \mathrm{~km}$ and depth $\geq 100 \mathrm{~km}$ respectively), and the recording stations were separated in along-arc and back-arc, according to their location. Figure 6 presents the observed $t^{*}$ as a function of hypocentral distance for both $\mathrm{P}$ and $\mathrm{S}$ waves, as well as for the average calculated from both horizontal components using both the automatic and manual approaches.

The results of Figure (6) show that no considerable linear trend revealing dependence of $t^{*}$ with distance could be observed on the original data, clearly a result of the significant spatial and depth variations of the anelastic attenuation structure. In order to further examine this issue, we studied the spatial variation of $t^{*}$ values. In general, along-arc stations present low values of $t^{*}$, while back-arc stations show much larger values. The observed $t *$ difference becomes more pronounced as the depth of the earthquakes increases revealing that attenuation is stronger for deeper events. For a more detailed view of the spatial variations of the whole path attenuation operator we performed an approximate interpolation of $\mathrm{t}^{*}$, mapping each path value in the middle of the ray path. Interpolation was carried out for all stations for $\mathrm{P}, \mathrm{S}$ and "mean $\mathrm{S}$ " waves using all the available $\mathrm{t}^{*}$ values calculated with both approaches, for the same depth classification mentioned above. Examples of the results of this initial approximate interpolation for S waves are shown in plots in Figure 7.

The spatial variation of $t^{*}$, as presented in Figure 7, display some interesting features. For hypocentral depths $50 \leq$ depth $\leq 80 \mathrm{~km}$ low values of $t^{*}$, appear to be sparsely observed mainly in the back-arc area, while large values are found throughout the for-arc area. As hypocentral depths increase $(80 \leq$ depth $\leq 100 \mathrm{~km})$, low values of the whole path attenuation operator expand on a larger area in the back-arc/volcanic arc region. Finally, at depths larger than $100 \mathrm{~km}$, very low values of $t^{*}$ are clearly seen throughout the whole volcanic arc and back-arc area, defining a much larger area with higher attenuation.

\section{Conclusions}

High-quality data from two temporary networks were used in order to gain insight into the attenuation properties in the broader S. Aegean area. The whole path attenuation $\mathrm{t}^{*}$ operator and the quality factor were determined by fitting seismic acceleration spectra adopting two independent approaches. Lateral variations of $t^{*}$ do not show any significant dependence of $t *$ with distance. To examine possible spatial variations we examined $t *$ in terms of focal depth and spatial variability. The results image a high attenuation area in the volcanic and back-arc region in accordance with $\mathrm{P}$ and $\mathrm{S}$ tomographic results (Papazachos et al., 1995, Papazachos and Nolet, 1997) which clearly outlines the spatial expanse of the low-velocity (high-attenuation) area beneath the Aegean volcanic arc. Attenuation is stronger for deeper events revealing that the source of the attenuation is the low-velocity mantle wedge above the subducting slab of the Mediterranean lithosphere, in accordance with earlier suggestions (Skarlatoudis et al., 2013). Further processing of the available data by inverting the observed $t^{*}$ values and constructing 1D and $3 \mathrm{D}$ tomographic models will reveal additional details on the attenuation structure of the whole S. Aegean area. 


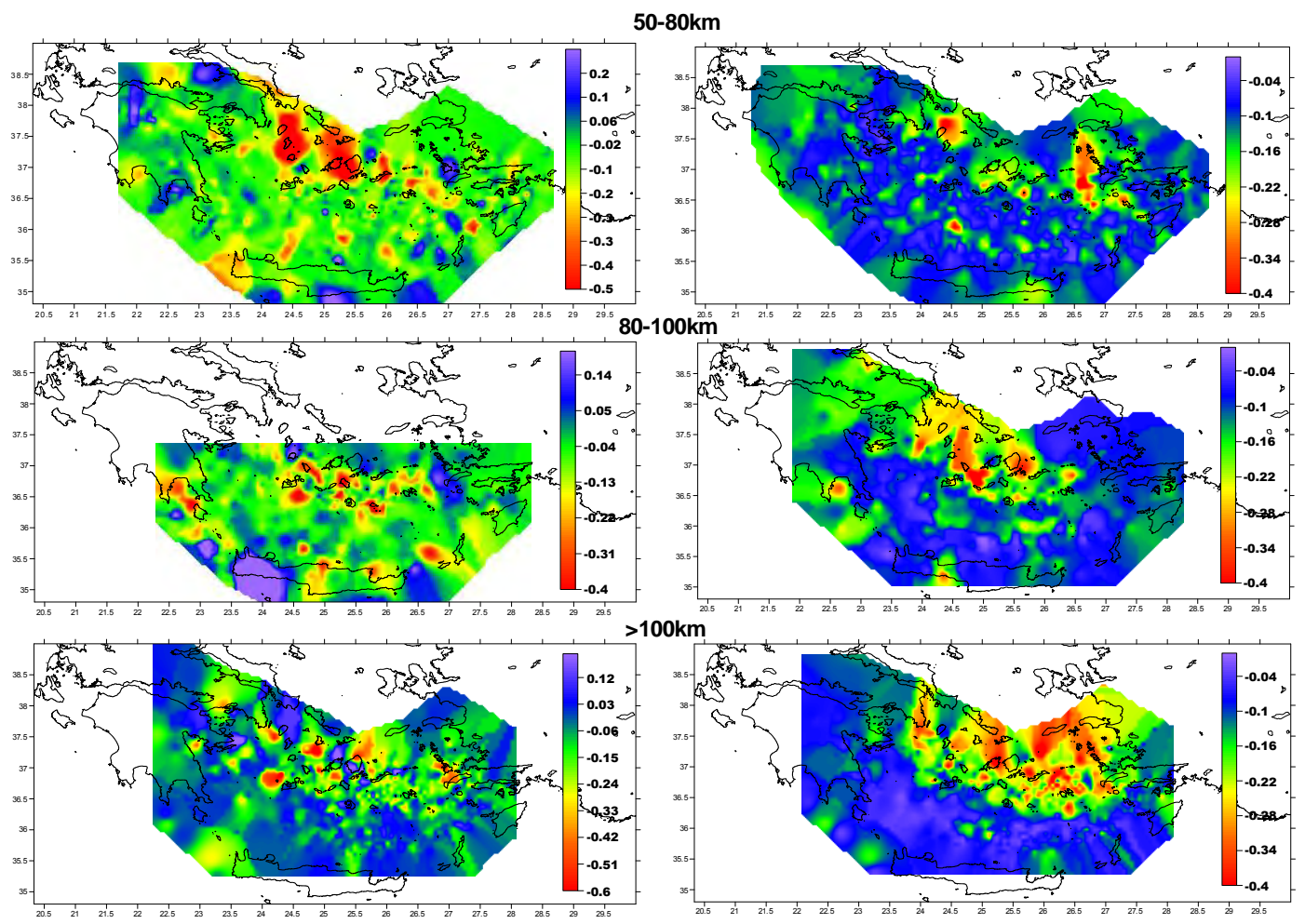

Figure 7 - Spatial variation of the $t^{*}$ for different focal depth ranges $(50-80 \mathrm{~km}, 80-100 \mathrm{~km}$, $>100 \mathrm{~km}$ ) for the southern Aegean subduction area. Red regions show areas with low $t^{*}$ values (higher attenuation), while green and blue regions areas with larger values. On the left column the corresponding spatial distribution with the use of the automatic method is presented, while on the right with the use of the manual one.

\section{Acknowledgments}

The GMT system (Wessel and Smith, 1998) was used to plot some figures. This work has been partly supported by the 3D-SEGMENTS project of the ARISTEIA-I call funded by EC European Social Fund and the Greek Secretariat of Research and Technology.

\section{References}

Bohnhoff M., Riche M., Meier T., Endrun B., Harjes H.P. and Stavrakakis G. 2004. A temporary seismic network of the Cyclades (Aegean Sea, Greece), Seismological Research Letters, $75 / 3,352-357$

Brune J.N. 1970. New Tectonic stress and the spectra of seismic shear waves from earthquakes, $J$. Geophys. Res., 75(26), 4997-5009.

Cormier V. F. 1982. The effect of attenuation on seismic body waves, Bull. Seism. Soc. Am. 72, . 169-200.

Kanamori H. 1967a. Attenuation of P-waves in the upper and lower mantle [with Japanese abs.]: Tokyo Univ. Earthquake Res. Inst. Bull., v. 45, 299-312.

McClusky S., Balasdsanian A., Barka C., Demir I,. Georgiev M., Hamburger K., Hurst K., Kastens G., Kekelidze R.K.V., Kotzev O., Lenk S., Mahmoud A., Mishin M., Nadariya A., Ouzounis D., Paradissis Y., Peter M., Prilepin R., Reilinger I., Sanli H., Seeger A., Tealeb M.N., Toksoz and Veis G. 2000. Global positioning system constraints on crustal move- 
ments and deformations in the eastern Mediterranean and Caucasus, Journal of Geophysical Research, 105, 5695-5719.

McKenzie D.P. 1972. Active tectonics of the Mediterranean region, Geophysical. J. R. astr. Soc., 30, 109-185.

Oral M.B., Reilinger R.E., Toksoz M.N., King R.W., Barka A.A., Kiniki J. and Lenk D. 1995. Global Positioning System offers evidence of plate motions in eastern Mediterranean, EOS, 76, 9-11.

Papazachos B. C. and Delibasis N. D. 1969. Tectonic stress field and seismic faulting in the area of Greece, Tectonophysics 7, 231-255.

Papazachos B. C. and Comninakis P. E. 1971. Geophysical and tectonic features of the Aegean arc, Journal of Geophysical Research 76, 8517-8533.

Papazachos C.B., Hatzidimitriou P.M., Panagiotopoulosn D., and Tsokas G.N. 1995. Tomography of the crust and upper mantle in SE Europe, J. Geophys. Res., 12, 405-12, 422.

Papazachos C.B., and Nolet G. 1997. P and S deep velocity structure of the Hellenic area obtained by robust non-linear inversion of travel times, J. Geophys. Res., 102, 8349-8367.

Papazachos B.C., Papaioannou C.A., Papazachos C.B. and Savvaidis A.S., 1999. Rupture zones in the Aegean region, Tectonophysics, 106, 71-85.

Papazachos B.C., Karakostas B.G., Papazachos C.B. and Scordilis E.M. 2000. The geometry of the Wadati - Benioff zone and lithospheric kinematics in the Hellenic arc, Tectonophysics, $319,275-300$.

Pozgay S.H., Wiens D.A., Conder J.A., Shiobara H. and Sugioka H. 2009. Seismic attenuation tomography of the Mariana subduction system: Implications for thermal structure, volatile distribution, and slow spreading dynamics, Geochem. Geophys. Geosyst., 10, Q04X05.

Reilinger R.E., McClusky S.C., Oral M.B., King R.W., Toksoz M.N., Barka A.A., Kinik I., Lenk O. and Sanli. I. 1997. Global positioning system measurements of present crustal movements in the Arabia-Africa-Eurasia plate collision zone, J. Geophys. Res. 102, 9983-9999.

Schurr B., Asch G., Rietbrock A., Trumbull R., Haberland C. 2003. Complex patterns of fluid and melt transport in the Central Andean subduction zone revealed by attenuation tomography, Earth Planet Sci Lett 215(1-2), 105-119.

Skarlatoudis A.A., Papazachos C.B., Margaris B.N., Ventouzi Ch., Kalogeras I. and the EGELADOS group, 2013. Ground motion prediction equations of intermediate-depth earthquakes in the Hellenic arc, southern Aegean subduction area, Bull. Seism. Soc. Am., in press.

Stachnik J., Abers G. and Christensen D. 2004. Seismic attenuation and mantle wedge temperatures in the Alaska subduction zone, Journal of Geophysical Research 109(B10): doi: 10.1029/2004JB003018. issn: 0148-0227. 